\title{
The influence of postgraduate qualifications on educational identity formation of healthcare professionals
}

\author{
Ahsan Sethi $^{1,2} \cdot$ Susie Schofield $^{2} \cdot$ Sean $_{\text {McAleer }^{2}} \cdot$ Rola Ajjawi $^{3}$
}

Received: 3 June 2017 / Accepted: 8 February 2018 / Published online: 16 February 2018

(C) The Author(s) 2018. This article is an open access publication

\begin{abstract}
Demand for postgraduate qualifications in medical education can be judged by the increase in providers worldwide over the last two decades. However, research into the impact of such courses on identity formation of healthcare professionals is limited. This study investigates the influence of such programmes on graduates' educational identities, practices and career progression. Informed by constructivist grounded theory (CGT), semistructured interviews were conducted with 27 graduates (2008-2012) from one postgraduate programme, who were at different stages in their careers worldwide. The audio data were transcribed and analysed using a CGT approach. Participants enrolled in award-bearing medical education courses for various intrinsic and extrinsic reasons. The findings from this study highlight their development as educators, and educational researchers, leaders and learners, as their self-efficacy in educational practices and engagement in scholarly activities increased. Graduates attributed career progression to the qualification, with many being promoted into senior positions. They also described substantial performance attainments in the workplace. The findings contribute to understanding the complexity and nuances of educational identity formation of healthcare professionals. A qualification in medical education encouraged transformational changes and epistemological development as an educator. Awareness of these findings will inform both those considering enrolment and those supporting them of potential benefits of these programmes.
\end{abstract}

Keywords Identity - Healthcare educators · Postgraduate qualifications · Communities of practice $\cdot$ Health professions education $\cdot$ Faculty development

Ahsan Sethi

ahsansethi@gmail.com

1 Institute of Health Professions Education \& Research, Khyber Medical University, Peshawar, Pakistan

2 Centre for Medical Education, University of Dundee, Dundee, UK

3 Centre for Research in Assessment and Digital Learning, Deakin University, Geelong, Australia 


\section{Introduction}

In recent years, interest in the professionalisation of medical education has grown (Bleakley et al. 2011; Sethi et al. 2016, 2017), driven mainly by increased public expectations, accountability and evidence-based education (Davis et al. 2005). This has led to an emergence of medical education associations supporting scholarship locally and globally, and to numerous peer-reviewed journals and books (Bleakley et al. 2011). Publications from the Liaison Committee on Medical Education (2014) and the General Medical Council (GMC $2005,2009,2012$ ) suggest a trend towards engaging doctors in effective pedagogical practices in all areas of undergraduate, postgraduate and continuing medical education. There is now a need for increased sophistication in healthcare education through the implementation of professional development initiatives (McLean et al. 2008). Formalised programmes in educational methods designed to support faculty members across their academic practice have developed from periodic sabbaticals, mentoring schemes, seminars and short courses (Steinert 2010).

Several higher education institutes offer awards such as a Postgraduate Certificate, Diploma or Master of Medical Education (Geraci et al. 2010). Such programmes aim to improve healthcare professionals' knowledge of educational practices (Cohen et al. 2005). Demand for these qualifications is evidenced by the increase in providers from 1996 to 2017 (from 7 to over 120 globally, from 2 to 31 in the United Kingdom (UK)) (see Table 1). O'Sullivan and Irby (2011) identified four different types of participants: (a) students and trainees, who teach but have little or no expertise, (b) faculty with minor teaching roles (c) faculty with major teaching roles and, (d) faculty interested in becoming full-time medical education researchers and faculty developers. They asserted that professional development programmes should vary according to the diverse nature of participants and their motivations for enrolment. Participants' motivations are directly related to learning, which in turn may influence the qualification's impact (Williams et al. 1999). Therefore, motivations for pursuing an advanced qualification in medical education is worthy of exploration when considering their impact.

Steinert et al. (2006) and Leslie et al. (2013) performed systematic reviews of studies of professional development initiatives in medical education. They found most to be course evaluations reporting participant satisfaction or gains in knowledge and skills. The studies were predominantly based on seminars, short courses and workshop-type interventions in the United States, Canada, Israel, Sweden and Germany. Few included longitudinal fellowship programmes, and none looked at award-bearing postgraduate programmes. One study found that completing a fellowship in medical education promoted fellows' confidence and identity as educators through strengthening their sense of self-efficacy, others' perceptions of credibility, and support from peers and mentors (Lown et al. 2009).

Until recently, the only studies published on postgraduate qualifications were UK scoping studies providing an overview of medical education programmes and the quality of Masters' research (Pugsley et al. 2008a, b). We previously reported on the self-reported Likert-graded long-term effects of postgraduate programmes on educational practices and scholarly activities (Sethi et al. 2016). The findings indicated that these qualifications enhanced theoretical foundations in educational practice resulting in increased self-efficacy and engagement in various educational scholarship activities, thus offering preliminary insights into how such programmes may influence professional identity formation.

Professional identity is the perception of oneself as a professional i.e. who one is, one's relationship with the profession, and how one's behaviour aligns with the norms and 


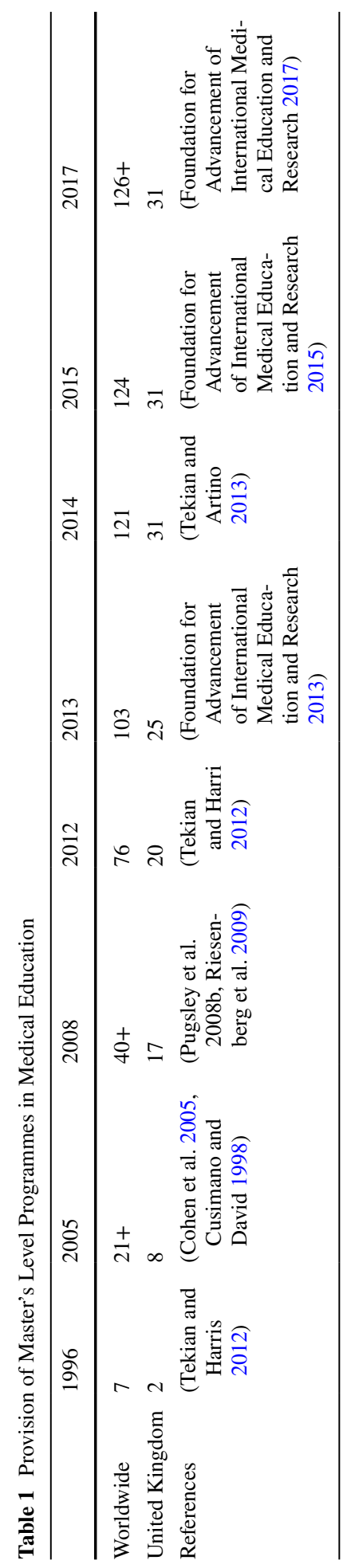


culture of a profession, based on interpretation and reinterpretation of interactions within the professional community (Monrouxe and Rees 2015). These identities are as important as knowledge and skills for success (Costello 2006; Rees 2009). Professional development initiatives can, and arguably should, have an impact on identity and careers in medical education.

We adopted Kelchterman's (1993) conceptual model to understand professional identity. This model describes the professional self and its influence on professional behaviours. It has been used to study the transformation process and development of professional identity among teachers (Abednia 2012; Anspal et al. 2012; Canrinus et al. 2012). The model has two dimensions: retrospective (the concept about self as one looks back from present to the past) and prospective (as one looks to the future). The retrospective dimension comprises four components:

1. Self-image: The general principles governing one's professional behaviour.

2. Self-esteem: Valuing and evaluating oneself as a professional, involving judgement of performance. Kelchtermans' definitions of teachers' self-image and self-esteem has links to teachers' self-efficacy, which is an indicator of professional identity (Canrinus et al. 2012).

3. Job motivation: Motives behind entering and staying in the profession. It also includes the commitment towards a profession and the factors affecting it.

4. Task perception: The understanding of one's professional responsibilities i.e. how individuals define their professional work, relationships and behaviours.

The prospective dimension comprises one component, future perspectives. It focuses on how professionals see their role or career progress in the future. Additionally, it includes their evaluation of the job situation and opportunities for future development.

\section{Rationale and research questions}

There is a need to look in-depth at the impact of award-bearing programmes on the identity formation of healthcare educators working in a diverse range of contexts worldwide, which may or may not be conducive for their newly learned educational practices. Understanding how participants learn the skills, attitudes and values needed to become active participants of the community, and develop an educational identity during the course, is necessary to tailor the support required in the transformation of beliefs and practices. Our overarching research question is:

How does a qualification in medical education influence graduates' educational identities, practices and career pathways?

\section{Theoretical framework}

Given our interests in professional identity formation, participation and careers, theories we considered relevant were Communities of Practice theory (Wenger 1998) and Social Cognitive Career theory (Lent et al. 1994), which itself is an extension of Social Cognitive theory (Bandura 1986). These provide the lenses through which to view learning/identity formation as social and situated.

Communities of Practice $(\mathrm{CoP})$ theory draws upon theories of situated experience and posits that the process of learning is closely interlinked with the construction of meaning 
and identity formation through shared practice (Wenger 1998). It states that identity is constructed through participation and interaction in a social activity (Bleakley et al. 2011). It responds to the dynamic nature of identity, recognising an individual's journey from joining a group, learning its professional culture, practices and language as a legitimate peripheral participant, through to core expert (Lave and Wenger 1991). This process involves real-life engagement in activities that have shared meaning for the participants along with an active exchange of knowledge between people and the social learning systems.

In education, CoP theory has been used to describe learning in virtual environments, institutions, higher research degrees and continuing professional development (Higgs et al. 2008; Blanton and Stylianou 2009). Its analytic perspectives may also be useful when considering the experiences of beginners in medical education as they develop a new professional identity. CoP theory's value in this study is in helping to highlight the social and cultural dimensions of learning, central features of belonging, participation and identity formation (Cantillon et al. 2016). Even though CoP theory is part of a broader concept for thinking about learning within social dimensions, it is compatible with theories addressing other dimensions of learning such as psychological and cognitive aspects (Wenger 2010).

Social Cognitive Theory (SCT) considers the unique ways in which individuals acquire and maintain behaviour, while also considering the social context (Bandura 1986). It posits a reciprocal and dynamic interaction between personal factors, environmental factors and individuals' behaviours. SCT emphasises that individuals learn by observing the behaviours of others, and, depending upon the expected outcomes, may use this learning to engage in subsequent behaviours. Self-efficacy plays a key role in mastering as well as performing those behaviours. However, this theory does not explicate the varying levels of influence of personal and environment factors.

One extension of SCT is Social Cognitive Career Theory (SCCT), which helps understand career-related interests and persistence in occupational pursuits (Lent et al. 1994; Brown and Lent 1996). Interest is necessary for meaningful participation in the learning process as identified by CoP theory (Wenger 1998). SCCT suggests that individuals develop interest and pursue and perform better in activities if they have strong selfefficacy and environmental support. It focusses on the role of self-efficacy and outcome expectations in setting goals, taking into account personal and environmental influences (Lent et al. 1994). However, self-efficacy cannot compensate for lack of task ability: underpinning knowledge and skills are pre-requisites (Ackerman et al. 2009). SCCT has been applied in career counselling to explain how educational career choices are made and how success can be obtained (Lent et al. 2006). In education, it has been used as a conceptual framework to explore the experiences of clinician-educators as they fulfil educational roles (Kumar et al. 2011; Bartle and Thistlethwaite 2014).

\section{Methods}

The Research Ethics Committee, University of Dundee granted the study ethical approval. The lead author (AS) is a dentist and medical educator, who had previously completed the Master of Medical Education at Dundee. He recruited participants and collected all the data. The other authors (SS, SM, RA) are academic medical educators with experience in qualitative research and were involved in the Dundee programme at the time of the study; therefore, data were de-identified before their involvement in the analysis. The insider research status of AS was beneficial in terms of ease of access, awareness of the context and work practices, familiarity with terminology used, and building rapport. This 
research did not seek to evaluate the programme, but instead utilised the context in order to shed light on an important educational phenomenon.

\section{Study design}

We used a constructivist grounded theory approach (Charmaz 2006) as it is considered useful for understanding the processes of professional practice and identity formation (Skeat 2010). It involves the construction of a theoretical explanation of a phenomenon based on gathering, synthesising, analysing and interpreting practical experiences of the participants. The data and its analysis are social constructions from shared experiences and relationships between researchers and research participants. However, it is important to remain reflexive so that any preconceived ideas are not forced upon the data to find a fit. Key decisions made during the data collection, management and analysis were discussed among the researchers before subsequent action, providing researcher triangulation.

\section{Study setting}

The Centre for Medical Education, University of Dundee, UK has 3438 graduates (1988-2017) at three levels: Postgraduate Certificate, Diploma and Masters. The Certificate and Diploma have a modular approach; a supervised research project completes the Masters. Students can study face-to-face, online distance or a combination of both, over a period of 1-6 years (previously nine). Entrants must have an educational or professional background in healthcare. About $90 \%$ are doctors, and $65 \%$ are UK-based.

\section{Data collection}

The study sample frame was those graduating from the programmes between 2008-2012 who had consented to be invited to participate in this qualitative study during the previous survey study (Sethi et al. 2016). Participation was voluntary. As CME graduates there were no existing power-over relations with the researchers. The sample size was not predetermined; instead an iterative approach of simultaneous data collection and analysis was taken until theoretical sufficiency was achieved (Dey 1999). In constructivist grounded theory, sufficiency is viewed at a conceptual rather than data level (Watling and Lingard 2012). It is achieved when the researcher has gained adequate understanding, and the identified themes are adequately accounted for (O'Reilly and Parker 2012). Potential participants were divided into strata on the basis of their level of qualification and year of graduation. Criteria were then defined for selection of sources i.e. graduating with Certificate 2008, 2012; Masters 2008, 2012. Initially 20 graduates (5 in each stratum) were invited via email. Of these, 11 graduates (2008: two Certificate, four Masters; 2012: three Certificate, two Masters) responded. The data were analysed, and more graduates invited iteratively from each of these strata for information intensity. This approach gives comparative data from participants with distinctively different experiences, perspectives and characteristics and allows for the refinement of ideas. Participants with unique attributes (e.g. age: $<30$ years or a $\mathrm{PhD}$ in medical education), outliers and negative cases from the survey study were also selected to increase the diversity of the sample and facilitate the delineation of concepts (Morse 1995).

AS carried out individual interviews for focused two-way communication which encouraged rich descriptions of participants' experiences (Dicicco-Bloom and Crabtree 
2006). The interview schedule was developed, piloted and revised by the research team. The questions were open-ended and based on the theoretical framework: exploring motivations, impact on career, professional identity and the workplace. Participants were also asked about specific educational changes resulting from the qualification.

Interviews were conducted over a five-month period (Oct 2013-Feb 2014) via landline, Skype and face-to-face meetings depending upon individual circumstances. Interviews were audio-recorded and transcribed verbatim by AS using Express Scribe. During transcription, a single comma can result in changing the entire meaning of a sentence (Bleakley 2005). Therefore, each recording was listened to alongside the transcription twice to promote rigour.

\section{Data analysis}

A constructivist grounded theory analysis (Charmaz 2006) was employed. During initial coding, three researchers (AS, SS, RA) studied four transcripts independently, ensuring that no single perspective dominated. The codes were identified through active interaction with the data and by carefully reading each line, incident and segment to construct codes for fit and relevance. They included in vivo analytic codes that preserve participants' meanings of their views and fluidity of their experiences, and present a fresh perspective on the experience (Charmaz 2006). By developing in vivo analytic codes, the data forms the foundation of the theory. The coding framework was refined continuously, through team discussions, as new data were collected and analysed. Data at each level of analysis were compared to find similarities and differences, thus refining the themes and establishing analytic distinctions (Skeat 2010).

The codes and associated data were categorised, and each theme compared across all the participants/groups. The participants were grouped based on qualification, year of graduation, age and nationality using query tool from ATLAS ti 7, in order to explore the effect of a particular demographic on the patterns of experience or behaviours. The data were interpreted from specific towards general concepts as a whole by searching for patterns, associations, concepts, and explanations (Skeat 2010). This abstraction helped to develop associations with various contextual factors, which is vital to the understanding of professional identity development (Starks and Trinidad 2007).

During the whole research process, spontaneous informal memos about codes or emerging ideas were added. These helped knit concepts together in new ways, which rely less on schematically ordering the concepts, and more on the feel for the data and abductive thinking that flits back and forth from the data to the abstracted concepts (Charmaz 2006). The memos were also an opportunity to weave in interpretations from theories (Kelchterman, $\mathrm{CoP}$ and SCCT) relevant to the data. Constant comparison and memo-writing promoted reflective thinking and theoretical dialogue with the data (Watling and Lingard 2012).

\section{Findings}

\section{Participant demographics}

The participants $(n=27)$ were at different stages in their careers, from different countries, and predominantly distance-learners (Table 2). Their educational roles included dean, director, professor, project leader, lecturer, clinical registrar and $\mathrm{PhD}$ student. 
Table 2 Characteristics of interview participants

\begin{tabular}{|c|c|}
\hline Characteristics & Frequency \\
\hline \multicolumn{2}{|l|}{ Gender } \\
\hline Male & 12 \\
\hline Female & 15 \\
\hline \multicolumn{2}{|l|}{ Age } \\
\hline Under 30 years & 1 \\
\hline 30-45 years & 13 \\
\hline Over 45 years & 13 \\
\hline \multicolumn{2}{|l|}{ Qualification } \\
\hline Certificate & 9 \\
\hline Diploma & $2^{*}$ \\
\hline Masters & 16 \\
\hline \multicolumn{2}{|l|}{ Mode } \\
\hline Face-to-face distance & 6 \\
\hline Learning & 20 \\
\hline Blended & 1 \\
\hline \multicolumn{2}{|l|}{ Profession } \\
\hline Medicine & 22 \\
\hline Medical education & 2 \\
\hline Dentistry & 1 \\
\hline Nursing & 1 \\
\hline Pharmacy & 1 \\
\hline \multicolumn{2}{|l|}{ Workplace } \\
\hline United Kingdom & 12 \\
\hline United States & 2 \\
\hline Canada & 2 \\
\hline Pakistan & 1 \\
\hline Thailand & 2 \\
\hline South Africa & 1 \\
\hline Australia & 2 \\
\hline Saudi Arabia & 1 \\
\hline Sri Lanka & 1 \\
\hline Chile & 1 \\
\hline Denmark & 1 \\
\hline Nepal & 1 \\
\hline
\end{tabular}

*Currently enrolled for Masters

We identified five themes associated with identity formation of healthcare educators: Motivations, Career Opportunities, Self-Efficacy, Development \& Changes in Practices, and Performance Attainments. Motivations, career opportunities, self-efficacy and performance attainments related to Kelchterman's (1993) identity model whilst self-efficacy and development and changes in practice related to learning and formation framed by CoP theory (Wenger 1998) and SCCT (Lent et al. 1994). The following section describes these themes, illustrated with quotations from participants coded by gender (Male/Female), and 
level of graduation (M: Masters, D: Diploma, C: Certificate). Other descriptors such as workplace are not included to preserve participants' anonymity.

\section{Motivations}

Healthcare professionals enrolling for medical education qualifications brought varied learning experiences based on personal and contextual factors. Multiple reasons for enrolment were identified, a desire to improve educational understanding and competency being the most common.

I was interested in education; I just wanted to know the theoretical aspects and to find out ways how I could improve my teaching' (Female C\#142)

For many participants, this intrinsic desire was associated with other extrinsic motivations, including: recommendations by colleagues and professional reviews, local requirement for educational reforms and academic positions, as part of their career pathway in medical education, and to enhance career prospects.

To basically pursue my plans of becoming a specialist medical educationalist (Male M\#81)

The participants who enrolled for extrinsic reasons gradually developed an interest in medical education, and many continued from Certificate to Diploma and Masters. Participants wanting to enhance career prospects or satisfy professional reviewers later in their career only enrolled for the Certificate. However, most of the international participants enrolled for the Masters, typically due to governmental or faculty funding regulations.

\section{Career opportunities}

Participants attributed their career progression to the qualification and this was associated with greater educational responsibilities. The Masters qualification acted as a steppingstone for a $\mathrm{PhD}$ and an academic career in medical education.

Had an opportunity to take on an extra role that's foundation programme director ... the fact that I had a postgraduate medical education qualification helped me get that post ... I don't think previously, I had the knowledge or experience even to put myself forward for some of these posts (Male M\#106)

Early career Masters' graduates also reported a shift of career towards medical education rather than clinical practice. Their increasing self-efficacy encouraged further participation in medical education.

Once I did the qualification, I moved solely towards this field, before I was both the clinician and in medical education but now I am predominantly ... studying medical education, working in medical education ... when I initially joined the course, I never intended to do more than a Masters. (Female M\#68)

\section{Self-efficacy}

Participants reported varying levels of self-efficacy based on their prior experiences. Irrespective of this level, they reported a further increase in self-efficacy after the qualification. The qualification enriched their understanding of core concepts in medical education and 
they reported better performance in various educational tasks, e.g., lesson planning, course evaluation and standard setting.

The process of doing the course has just made me more confident ... so people give me things to do and then I find that I am very confident in doing them (Female M\#73)

The data also suggested that participants' self-efficacy was dynamic and continuously derived both from their performance attainments as students during the course and as professionals in the workplace. Strong self-efficacy in medical education contributed towards pursuing it as a career choice and also affected motivations towards related tasks.

I started with the certificate and ... I was receiving very highly appreciating feedback from tutors, so I started to think that I had to continue ... I took it very serious and I proceeded to Masters' degree (Male M\#30)

\section{Development and changes in practices}

The analysis also highlighted the transformational changes and development of graduates as teachers, researchers, leaders and learners. Undertaking the qualification made them critically analyse their teaching, and they found evidence-based strategies helpful in becoming effective teachers. Participants gave many examples of their development as facilitator, assessor, planner, developer, mentor, feedback provider and role model.

[I'm] more into peer group and student-centred [teaching]... I would not have known how to facilitate [learning] ... earlier on (Female C\#142)

Participants also learned about various research paradigms and methods during the course. Masters graduates were able to implement their learning in the form of a research dissertation, with many continuing educational research after the qualification and reporting several publications.

I now do some education research and I have published three education papers in the last 18 months, that's something I would have never done before (Male M\#18)

Various leadership characteristics such as recognition/legitimacy, supportive behaviour and seeking constructive changes in their organisations were described. The graduates gave specific examples of educational changes, indicating impact of the qualification at organisational level.

I am certainly viewed as an educational leader in my current position ... many other departments consult me (Male M\#81)

The graduates developed as learners. They reported critically reflecting on their educational beliefs in order to improve their educational practices. They highlighted the essential role of evidence in educational decision-making and the need to continue to learn about education following graduation.

The biggest shift is about kinda standing back and critically thinking more, reflecting so if we are doing something ... I'd be more inclined just to step back and say ... Why are we doing it? Why we are doing it this way? ... What's the better evidence for suggesting this? Is this the right approach or not? (Male M\#34) 


\section{Performance attainments}

Participants led various educational activities and innovations such as faculty development, curriculum reforms, course organisation and evaluations at institutional, national and international level. These activities resulted in substantial performance attainments including personal satisfaction, commendations, better external reviews and highly positive student/ peer feedback. Some Masters' graduates noted winning competitive grants for educational projects, while others reported obtaining course accreditation and registrations for their institutes. Participants were particularly pleased with their own students' marked improvement in performance.

Since I have improved teaching and ... changed the assessment practice ... the pass rate has gone up and the students are getting through the course much more as they should in the time scale ... we are not finding that the good students are suddenly failing something because the assessment is poor (Female M\#89)

Performance attainments in the workplace fed back into participants' learning experiences in an incremental iterative process. We use the term 'incremental iterative process' to convey the dynamic longitudinal nature of identity formation. This term has been used in software development, where the software is built in smaller sections, and the software is then used and built further based on learning derived from it in repeated cycles (Larman and Basili 2003). As the vast majority of participants were studying part-time in their institutions as distance learners, they applied their learning from the course to day-to-day educational practices during this time, and used these workplace experiences to make sense of the theoretical components of study.

It became much easier to do the [study] modules ... I kind of timed it you know having it with OSCEs was a good time to do the module on OSCE ... it made much more contextual sense because you were doing the stuff as well as reading about it and you know writing it up ... to be able to read around the kind of underlying theory about it at the same time. (Male M\#34)

Their increasing self-efficacy and competency continuously encouraged further participation in scholarly medical education activities. The participants learned the language of the educational community, leading to an increased sense of belonging to a community of practice.

I think it has given me a better vocabulary with which to discuss issues with people (Female C\#178)

During this interaction with the educational community, they not only learned from the community but also played an active role in its further development.

After my qualification and with the progress I made they decided to recruit new people for medical education and now it's an effective centre ... it plays a major role in running the curriculum ... it's going to be a department in the future (Male M\#59)

However, graduates' personal and contextual factors also influenced their self-efficacy in educational tasks and productivity in the workplace, sometimes reducing the impact of the qualification.

My thesis was around ... curriculum development so I ... can legitimately provide input into ... curricula ... [but] my role in my division has changed, where I do not 
have to deal with anything in curriculum development and it's pretty lowered down in terms of what my division wants me to do (Male M\#94)

\section{Discussion}

Motivation, self-efficacy and taking part in legitimate educational activities, afforded by the programs, are influences for the development of self-image and a professional identity. Based on personal and contextual factors, participants described a mix of intrinsic and extrinsic motivations towards enrolling for a medical education qualification. Participants reported a positive impact of the postgraduate qualifications on their personal and professional development. This development encompassed increased knowledge, transformational changes in practices and recognition as educators by self and others. Through the qualification, there were opportunities to take on leadership positions and pursue higher career trajectories, with expanded responsibilities in medical education. As their educational roles developed, the graduates translated their learning to practice with various performance attainments. However, personal and contextual factors strongly influenced their performance attainments in the workplace. The attainments gave the graduates a sense of achievement and fed back into their learning experiences, resulting in further development of interest and self-efficacy, strengthening their self-image and sense of belonging to the educational community. This in turn led to increased participation in various medical education activities. During this continuous interaction with educational activities while doing the qualification and in the workplace, participants actively integrated personal beliefs and the norms and values of the community. The longer periods of professional training provided opportunities for further socialisation into the community and this in turn fostered their educational identity described in an iterative and incremental fashion.

\section{Motivation for enrolment}

Many of our participants demonstrated both intrinsic and extrinsic motivators for enrolling on the programmes. Intrinsic motivation for learning is theorised to promote selfregulation, which mediates better conceptual understanding with enhanced performance and achievements in learning tasks (Walker et al. 2006; Lee et al. 2014). Wenger (1998) emphasised the importance of meaningful participation in a CoP for learning to occur. It is this meaningful engagement which gives educators a sense of who they are and their roles within society (Bleakley et al. 2011). Conversely, extrinsic motivators are correlated with superficial engagement and shallow processing of learning material (Walker et al. 2006). Pursuing any task involves a complex interplay of both intrinsic and extrinsic motivations, as was demonstrated by many of our participants.

Blackburn et al. (1991) suggested that an individual's involvement in certain activities is influenced by their perception of organisational priorities, which in turn also affects their assessment of personal abilities and interests. Personal factors are associated with cognitive and affective states that may impact our behaviours and responses to contextual factors. Such influences have been acknowledged by Bandura (1986), emphasising that our behaviours are a by-product of interplay between personal and environmental factors. The extrinsic motivations identified in this study suggest an increasing recognition of medical education as a speciality, with further investment, and its uptake being encouraged in various contexts (Tekian and Artino 2013). Most of the sample's international participants enrolled 
for the full Masters, suggesting it may be a more authentic exit point for full-time medical educators overseas. Goldszmidt et al. (2008) found no association between formal training of medical faculty in education and their future interest in pursuing education scholarship. They concluded that an advanced education programme might not be enough to increase involvement in educational scholarship unless supported by the workplace environment. This is in contrast with our findings, where participants reported an evolving interest, with increased participation in medical education, and higher levels of scholarly activity in those who graduated with a Masters as opposed to a Certificate (Sethi et al. 2016).

\section{Self-efficacy}

Lown et al. (2009) suggested that a key factor in identity formation among educators is having a strong knowledge of educational principles and applied skills. In our study, graduates reported a greater sense of empowerment and self-efficacy in educational practices as a result of undertaking their degree. Self-efficacy is central to actions, and influences what people choose to do, how much effort they invest in activities, how long they persist in the face of adversity, and whether they approach the tasks anxiously or assuredly (Kaufman 2003). Although strong self-efficacy alone is a predictor for career choice and performance, having an interest and/or extrinsic motivation would further strengthen the uptake of a course in medical education (Lent et al. 2006). Self-efficacy and intrinsic motivation are positively correlated with meaningful cognitive engagement and subsequent performance (Walker et al. 2006).

\section{Development and Influence on educational identities}

The graduates also experienced transformational changes with development as teacher, researcher, leader and learner. Participants reported learning new teaching skills, becoming learner-centred and showed development in various roles of the teacher. They developed the capabilities of being an effective medical educator as identified in the literature such as knowledge of educational theory, role modelling, showing respect for learners and giving appropriate feedback (McLean 2001; Thurgur et al. 2005; Duvivier et al. 2009). They also developed as mentors, which has been cited as a catalyst for facilitating career satisfaction, selection, advancement and productivity for peers and students (Sambunjak et al. 2006).

The graduates reported shifts in leadership capacity and felt empowered to take on new challenges to effect institutional change and implement educational innovations. This ability to challenge the status quo shows successful internalisation and understanding of the intricate and nuanced ways in which educational practices occur and change. It also represents ways in which individuals preserve their newly formed identities (Ewick and Silbey 2003; Monrouxe 2010).

The graduates reported that the qualification conferred legitimacy on their educational roles, giving them recognition as educational leaders, which itself further facilitated the implementation of educational changes. According to Northouse (2013), a leader can derive personal power from being seen by followers as knowledgeable/competent or can have position power from their rank in a formal organisation. The graduates not only helped their students but also colleagues in their educational practices. Such supportive behaviours are characteristic of being a leader (Northouse 2013). Studies looking at faculty interventions in medical education leadership have found similar results (Steinert et al. 2003; Robins et al. 2006; Searle et al. 2006). However, many of these required 
commitments from their superiors to mentor and support their activities. Our participants, enrolled in postgraduate qualifications in medical education at an institution not affiliated to their workplace, were internally motivated to mentor.

Our participants reported developing collaborations, delivering seminars and gaining peer-reviewed educational publications. Hence, postgraduate programmes are not only a product of the professionalisation of medical education, but their graduates also contribute further towards professionalisation of the field. Unsurprisingly, only Masters' graduates in our study reported developing as researchers. This may be due to applying the research paradigms and methods they have studied to an original research topic of interest to them, supported by one-to-one supervision. Absence of such supervision has been reported as a barrier to writing for publications in medical education (Simpson et al. 2000). Goldszmidt et al. (2008) also found that protected time, exposure to the literature, linkages with fulltime researchers and completion of a dissertation as part of their degree impacts on the ability to do research.

The roles of a medical educator as a teacher, leader and researcher have been recognised by Bligh and Brice (2009) as three vertices of an equilateral triangle. Our participants demonstrated that they also developed as learners. They reported becoming reflective in their educational practices along with subsequent engagement with the literature to validate or reject these practices. This is an important educational objective for adult learners and a key to transforming one's taken-for-granted assumptions, norms and practices (Mezirow 1997). It also allows learners to evaluate and identify specific learning needs (Boud et al. 2013). Moreover, the qualification heightened participants' sense of how much more there was to know, and the graduates developed an acute sense of the need to improve and become self-directed lifelong learners.

The experience of involvement in the activities of the community and desire to become an integral part is known as the concept of belongingness (Levett-Jones et al. 2007), central to CoP theory and identity formation (Wenger 1998). It involves being recognised, valued and accepted by other members of the community. The graduates also experienced an increased sense of belonging towards the medical education community after the qualification. Through this participation in educational activities, one begins to identify with one's role as an educator (Wenger 1998). This sense of belonging is fundamental to development, progress and success in a profession (Levett-Jones and Lathlean 2008), and may also explain why completion of the dissertation led to professional identity as an educational researcher.

\section{Influence on career pathway}

Career growth was directly attributed to the qualification, with graduates reporting new job opportunities, leadership positions and academic promotions with greater educational responsibilities. Academic promotions and career progress have also been reported by longitudinal programmes from the USA (Robins et al. 2006; Steinert and McLeod 2006). However, the selection criteria for those programmes demanded good credentials and strong commitment from applicants towards medical education. In our study, those obtaining a Masters' degree early in their career also started working solely in the field of medical education. This could be on account of an influence of the qualification or because the participants enrolled for the qualification at a particular time during their careers when they were open to new ways of thinking and being. For some the impact was so powerful that they reported the pursuit of advanced studies in medical education such as a $\mathrm{PhD}$. Such 
consideration suggests a drive towards obtaining further research capacity and credence as leaders among early career medical educators.

\section{Performance attainments}

Graduates reported leading various educational changes at institutional, national and international level, which resulted in performance attainments, which in turn increased their self-efficacy. The majority of our graduates were distance learners who were able to apply learning from the course to their day-to-day educational practices while doing the qualification. They could then reflect on their workplace experiences with reference to learning materials and support from their educators and colleagues. Productivity was also described by fellows from McGill University's Teaching Scholars Program (Steinert and McLeod 2006). However, their fellows had previous experience in medical education and workplace conditions conducive to productivity, which was not always the case for participants in our study.

\section{Implications}

Our findings explain how the professional culture and practices are learnt alongside knowledge and skills, thus continuously shaping roles and identities. It highlights the roles of formal education and the workplace in the learning process. The participants seek to integrate their actions and thinking with their new community and become attuned to the ways of being in the practices which they employ within the workplace. This construction and coconstruction of meaning during continuous interactions of the self with the educational and workplace communities results in professional identity formation (Rees 2009). Their evolving identities then influence their decisions and external actions. Identity is thus formed through the interplay of individuals and learning cultures influencing each other. Awareness of these findings will inform those considering enrolment and those supporting them of potential benefits of these programmes. A Certificate is suited to any whose work contains some teaching. Continuing to Diploma and Masters' qualification results in further gains in terms of career progression and research publications in medical education. Therefore, a Masters is appropriate not only for those pursuing a full-time educational career but for any wishing to develop as a researcher in medical education.

\section{Strengths and limitations}

Our findings are based on graduates self-reporting rather than observing behaviours, though it could be argued self-reporting is appropriate when looking at self-efficacy. Although graduates were from only one programme, they were dispersed across workplaces, contexts and geographically. Yin (2013) argues that case study research closely examines data within a specific context and provides detailed insights into the behaviours when little information is available regarding a contemporary phenomenon. By the nature of those who volunteer to take part in such research, it is likely that those who are motivated and feel an affiliation to medical education would have chosen to participate in the study. However, there has been no censuring of data, and negative experiences were forthcoming. Many graduates took 2-9 years in doing the qualification, making it sometimes difficult to differentiate between what was attributable to the qualification and what they learned from experience, mentors and other development activities. This can be related to 
memory, but it may also be due to the iterative incremental process of learning. The crosssectional nature of the study is another limitation of studying identity formation, which is clearly a dynamic process.

\section{Conclusion}

This is the first qualitative study looking in-depth at the influence of postgraduate qualifications in medical education on the healthcare professionals worldwide. Such qualifications encourage transformational changes and development as a teacher, leader, researcher and learner. We offer a more nuanced understanding of the influences on educational identity formation of healthcare professionals. Future research should study a cohort longitudinally through the course and beyond to explore the influence of context on professional identity formation. This would facilitate exploration of programme design features associated with transformational changes.

Acknowledgements The authors would like to thank all the participants for their time and the Khyber Medical University, Pakistan for funding AS's PhD candidature.

Author's Contribution AS conducted this research as part of his Ph.D. at the University of Dundee. All authors were involved in the design and conceptual framing of the study. AS secured ethics approval and collected and transcribed the data. All authors were involved in data analysis and contributed to the development of the model. All contributed to the writing of the paper and approved the final version.

\section{Compliance with ethical standards}

Conflict of interest The authors report no conflict of interest relevant to this article.

Open Access This article is distributed under the terms of the Creative Commons Attribution 4.0 International License (http://creativecommons.org/licenses/by/4.0/), which permits unrestricted use, distribution, and reproduction in any medium, provided you give appropriate credit to the original author(s) and the source, provide a link to the Creative Commons license, and indicate if changes were made.

\section{References}

Abednia, A. (2012). Teachers' professional identity: Contributions of a critical EFL teacher education course in Iran. Teaching and Teacher Education, 28, 706-717.

Ackerman, A., Graham, M., Schmidt, H., Stern, D. T., \& Miller, S. Z. (2009). Critical events in the lives of interns. Journal of General Internal Medicine, 24, 27-32.

Anspal, T., Eisenschmidt, E., \& Löfström, E. (2012). Finding myself as a teacher: Exploring the shaping of teacher identities through student teachers' narratives. Teachers and Teaching, 18, 197-216.

Bandura, A. (1986). Social foundations of thought and action: A social cognitive theory/Albert Bandura. N.J., Prentice-Hall: Englewood Cliffs.

Bartle, E., \& Thistlethwaite, J. (2014). Becoming a medical educator: Motivation, socialisation and navigation. BMC Med Educ, 14, 110.

Blackburn, R. T., Bieber, J. P., Lawrence, J. H., \& Trautvetter, L. (1991). Faculty at work: Focus on research, scholarship, and service. Research in Higher Education, 32, 385-413.

Blanton, M. L., \& Stylianou, D. A. (2009). Interpreting a community of practice perspective in disciplinespecific professional development in higher education. Innovative Higher Education, 34, 79-92.

Bleakley, A. (2005). Stories as data, data as stories: Making sense of narrative inquiry in clinical education. Medical Education, 39, 534-540.

Bleakley, A., Bligh, J., \& Browne, J. (2011). Medical education for the future: Identity, power and location. Dordrecht Heidelberg London New York: Springer. 
Bligh, J., \& Brice, J. (2009). Further insights into the roles of the medical educator: The importance of scholarly management. Academic Medicine, 84, 1161-1165.

Boud, D., Keogh, R., \& Walker, D. (2013). Reflection: Turning experience into learning. Oxford: Routledge.

Brown, S. D., \& Lent, R. W. (1996). A social cognitive framework for career choice counseling. The Career Development Quarterly, 44, 354-366.

Canrinus, E. T., Helms-Lorenz, M., Beijaard, D., Buitink, J., \& Hofman, A. (2012). Self-efficacy, job satisfaction, motivation and commitment: Exploring the relationships between indicators of teachers' professional identity. European Journal of Psychology of Education, 27, 115-132.

Cantillon, P., D’Eath, M., De Grave, W., \& Dornan, T. (2016). How do clinicians become teachers? A communities of practice perspective. Advances in Health Sciences Education, 21, 991-1008.

Charmaz, K. (2006). Constructing grounded theory: A practical guide through qualitative analysis. London: Sage Publications.

Cohen, R., Murnaghan, L., Collins, J., \& Pratt, D. (2005). An update on master's degrees in medical education. Medical Teacher, 27, 686-692.

Costello, C. Y. (2006). Professional identity crisis: Race, class, gender, and success at professional schools. Tennessee: Vanderbilt University Press.

Cusimano, M. D., \& David, M. A. (1998). A compendium of higher education opportunities in health professions education. Academic Medicine, 73, 1255-1259.

Davis, M. H., Karunathilake, I., \& Harden, R. M. (2005). AMEE Education Guide no. 28: The development and role of departments of medical education. Medical Teacher, 27, 665-675.

Dey, I. (1999). Grounding grounded theory: Guidelines for qualitative inquiry. San Diego: Academic Press.

Dicicco-Bloom, B., \& Crabtree, B. F. (2006). The qualitative research interview. Medical Education, 40, 314-321.

Duvivier, R., Van Dalen, J., Van Der Vleuten, C., \& Scherpbier, A. (2009). Teacher perceptions of desired qualities, competencies and strategies for clinical skills teachers. Medical Teacher, 31, 634-641.

Ewick, P., \& Silbey, S. (2003). Narrating social structure: Stories of resistance to legal authority. American Journal of Sociology, 108, 1328-1372.

Foundation for Advancement of International Medical Education and Research. (2013). Master's Programs in Health Professions Education. [Online]. Available: http://www.faimer.org/resources/mastersmed ed.html [Accessed May 20 2013].

Foundation for Advancement of International Medical Education and Research. (2015). Master's Programs in Health Professions Education. [Online]. Available: http://www.faimer.org/resources/mastersmed ed.html [Accessed August 8 2015].

Foundation for Advancement of International Medical Education and Research. (2017). Master's Programs in Health Professions Education. [Online]. Available: http://www.faimer.org/resources/mastersmed ed.html [Accessed May 27 2017].

Geraci, S. A., Kovach, R. A., Babbott, S. F., Hollander, H., Buranosky, R., Devine, D. R., et al. (2010). Alliance for Academic Internal Medicine report on master teachers and clinician educators part 2: Faculty development and training. The American Journal of Medicine, 123(869-872), e6.

GMC. (2005). The new doctor-Guidance on PRHO training. [Online]. General Medical Council. Available: http://www.gmc-uk.org/The_New_Doctor_2005.pdf_25397189.pdf [Accessed May 5 2013].

GMC. (2009). Tomorrow's Doctors-Outcomes and standards for undergraduate medical education. [Online]. General Medical Council. Available: http://www.gmc-uk.org/Tomorrow_s_Doctors_1214. pdf_48905759.pdf [Accessed May 5 2013].

GMC. (2012). Recognition and approval of trainers. [Online]. Available: http://www.gmc-uk.org/educa tion/10264.asp\#1 [Accessed March 10 2013].

Goldszmidt, M. A., Zibrowski, E. M., \& Weston, W. W. (2008). Education scholarship: It's not just a question of degree. Medical Teacher, 30, 34-39.

Higgs, J., Aijawi, R., \& Smith, M. (2008). Working and learning in communities of practice. In J. Higgs, M. Smith, G. Webb, M. Skinner, \& A. Croker (Eds.), Contexts of physiotherapy practice. Sydney: Churchill Livingstone.

Kaufman, D. M. (2003). ABC of learning and teaching in medicine: Applying educational theory in practice. British Medical Journal, 326, 213-216.

Kelchtermans, G. (1993). Getting the story, understanding the lives: From career stories to teachers' professional development. Teaching and Teacher Education, 9, 443-456.

Kumar, K., Roberts, C., \& Thistlethwaite, J. (2011). Entering and navigating academic medicine: Academic clinician-educators' experiences. Medical Education, 45, 497-503.

Larman, C., \& Basili, V. R. (2003). Iterative and incremental development: A brief history. Computer, 36, 47-56. 
Lave, J., \& Wenger, E. (1991). Situated learning: Legitimate peripheral participation. Cambridge: Cambridge University Press.

Lee, W., Lee, M.-J., \& Bong, M. (2014). Testing interest and self-efficacy as predictors of academic selfregulation and achievement. Contemporary Educational Psychology, 39, 86-99.

Lent, R. W., Brown, S. D., \& Hackett, G. (1994). Toward a unifying social cognitive theory of career and academic interest, choice, and performance. Journal of Vocational Behavior, 45, 79-122.

Lent, R. W., Brown, S. D., \& Hackett, G. (2006). Social cognitive career theory. In J. H. Greenhaus, G. A. Callanan, \& D. E. Gibson (Eds.), Encyclopedia of career development. Thousand Oaks: SAGE Publications Inc.

Leslie, K., Baker, L., Egan-Lee, E., Esdaile, M., \& Reeves, S. (2013). Advancing faculty development in medical education: A systematic review. Academic Medicine, 88, 1038-1045.

Levett-Jones, T., \& Lathlean, J. (2008). Belongingness: A prerequisite for nursing students' clinical learning. Nurse Education in Practice, 8, 103-111.

Levett-Jones, T., Lathlean, J., Maguire, J., \& McMillan, M. (2007). Belongingness: A critique of the concept and implications for nursing education. Nurse Education Today, 27, 210-218.

Liaison Committee on Medical Education. (2014). Functions and structure of a Medical School-Standards for Accreditation of Medical Education Programs Leading to the M.D. Degree. [Online]. Available: http://www.lcme.org/publications.htm [Accessed 12 June 2014].

Lown, B. A., Newman, L. R., \& Hatem, C. J. (2009). The personal and professional impact of a fellowship in medical education. Academic Medicine, 84, 1089-1097.

McLean, M. (2001). Qualities attributed to an ideal educator by medical students: Should faculty take cognizance? Medical Teacher, 23, 367-370.

McLean, M., Cilliers, F., \& Van Wyk, J. M. (2008). Faculty development: Yesterday, today and tomorrow. Medical Teacher, 30, 555-584.

Mezirow, J. (1997). Transformative learning: Theory to practice. New Directions for Adult and Continuing Education, 1997, 5-12.

Monrouxe, L. V. (2010). Identity, identification and medical education: Why should we care? Medical Education, 44, 40-49.

Monrouxe, L. V., \& Rees, C. E. (2015). Theoretical Perspectives on identity: Researching identities in healthcare education. In J. Cleland \& S. J. Durning (Eds.), Researching medical education. Chichester: John Wiley \& Sons.

Morse, J. M. (1995). The significance of saturation. Qualitative Health Research, 5, 147-149.

Northouse, P. G. (2013). Leadership: Theory and practice. London: Sage Publications.

O'Reilly, M. \& Parker, N. (2012). 'Unsatisfactory Saturation': A critical exploration of the notion of saturated sample sizes in qualitative research. Qualitative Research, 13, 190-197.

O’Sullivan, P. S., \& Irby, D. M. (2011). Reframing research on faculty development. Academic Medicine, $86,421-428$.

Pugsley, L., Brigley, S., Allery, L., \& Macdonald, J. (2008a). Counting quality because quality counts: Differing standards in master's in medical education programmes. Medical Teacher, 30, 80-85.

Pugsley, L., Brigley, S., Allery, L., \& MacDonald, J. (2008b). Making a difference: Researching master's and doctoral research programmes in medical education. Medical Education, 42, 157-163.

Rees, C. E. (2009). Identities as performances: Encouraging visual methodologies in medical education research. Medical Education, 44, 5-7.

Riesenberg, L. A., Little, B. W., \& Wright, V. (2009). Nonphysician medical educators: A literature review and job description resource. Academic Medicine, 84, 1078-1088.

Robins, L., Ambrozy, D., \& Pinsky, L. E. (2006). Promoting academic excellence through leadership development at the University of Washington: The Teaching Scholars Program. Academic Medicine, 81, 979-983.

Sambunjak, D., Straus, S. E., \& Marušić, A. (2006). Mentoring in academic medicine: A systematic review. Journal of American Medical Association, 296, 1103-1115.

Searle, N. S., Thompson, B. M., \& Perkowski, L. C. (2006). Making it work: The evolution of a medical educational fellowship program. Academic Medicine, 81, 984-989.

Sethi, A., Ajjawi, R., McAleer, S., \& Schofield, S. (2017). Exploring the tensions of being and becoming a medical educator. BMC Medical Education, 17, 62.

Sethi, A., Schofield, S., Ajjawi, R., \& Mcaleer, S. (2016). How do postgraduate qualifications in medical education impact on health professionals? Medical Teacher, 38, 162-167.

Simpson, D. E., Mclaughlin, C., \& Schiedermayer, D. (2000). Writing "Blitzes” for Medical Educators. Academic Medicine, 75, 555.

Skeat, J. (2010). Using grounded theory in health research. In P. Liamputtong (Ed.), Research methods in health: Foundations for evidence-based practice. Oxford: Oxford University Press. 
Starks, H., \& Trinidad, S. B. (2007). Choose your method: A comparison of phenomenology, discourse analysis, and grounded theory. Qualitative Health Research, 17, 1372-1380.

Steinert, Y. (2010). Faculty development: From workshops to communities of practice. Medical Teacher, 32, 425-428.

Steinert, Y., Mann, K., Centeno, A., Dolmans, D., Spencer, J., Gelula, M., et al. (2006). A systematic review of faculty development initiatives designed to improve teaching effectiveness in medical education: BEME Guide No. 8. Medical Teacher, 28, 497-526.

Steinert, Y., \& McLeod, P. J. (2006). From novice to informed educator: The teaching scholars program for educators in the health sciences. Academic Medicine, 81, 969-974.

Steinert, Y., Nasmith, L., McLeod, P. J., \& Conochie, L. (2003). A teaching scholars program to develop leaders in medical education. Academic Medicine, 78, 142-149.

Tekian, A., \& Artino, A. R., Jr. (2013). AM last page: Master's degree in health professions education programs. Academic Medicine, 88, 1399.

Tekian, A., \& Harris, I. (2012). Preparing health professions education leaders worldwide: A description of masters-level programs. Medical Teacher, 34, 52-58.

Thurgur, L., Bandiera, G., Lee, S., \& Tiberius, R. (2005). What do emergency medicine learners want from their teachers? A multicenter focus group analysis. Academic Emergency Medicine, 12, 856-861.

Walker, C. O., Greene, B. A., \& Mansell, R. A. (2006). Identification with academics, intrinsic/extrinsic motivation, and self-efficacy as predictors of cognitive engagement. Learning and Individual Differences, $16,1-12$.

Watling, C. J., \& Lingard, L. (2012). Grounded theory in medical education research: AMEE Guide No. 70. Medical Teacher, 34, 850-861.

Wenger, E. (1998). Communities of practice: Learning, meaning, and identity. Cambridge: Cambridge University Press.

Wenger, E. (2010). Communities of practice and social learning systems: The career of a concept. In C. Blackmore (Ed.), Social learning systems and communities of practice. London: Springer.

Williams, G. C., Saizow, R. B., \& Ryan, R. M. (1999). The importance of self-determination theory for medical education. Academic Medicine, 74, 992-995.

Yin, R. K. (2013). Case study research: Design and methods. London: Sage Publications. 